\section{Key words}

polycyclic aromatic hydrocarbons

paracyclophanes

pentacenes

charge transfer

R. BULA, M. FINGERLE, A. RUFF, B. SPEISER, C. MAICHLE-MÖSSMER, H. F. BETTINGER* (UNIVERSITÄT TÜBINGEN AND UNIVERSITÄT STUTTGART, GERMANY)

Anti-[2.2](1,4)pentacenophane: A Covalently Coupled Pentacene Dimer

Angew. Chem. Int. Ed. 2013, 52, 11647-11650.

\title{
Pentacenes Communicate Through Space
}



Significance: Due to their demonstrated utility in optoelectronic devices, polyacenes continue to garner attention as fascinating systems for studying the fundamental properties that are responsible for their observed behavior. The authors contribute to the study of charge-transfer communication between pentacenes by creatively expanding on the concept of covalently coupled anthracenes developed by the Misumi group in the 1970s (Tetrahedron Lett. 1972, 13, 1731). Preliminary characterization of $\mathbf{6}$ via UV/Vis spectroscopy, DFT modeling, and cyclic voltammetry provides a useful benchmark for future studies of this class of compounds.

SYNFACTS Contributors: Timothy M. Swager, Joseph M. Azzarelli Synfacts 2014, 10(1), 0032 Published online: 13.12.2013 Dol: 10.1055/s-0033-1340388; Reg-No.: S14413SF
Comment: Applying de Meijere's method (Chem. Ber. 1993, 126, 2531) of accessing pseudo-para tetrabromide $\mathbf{2}$ and cycloadducts $\mathbf{3}$ is a clever approach to constructing anti-[2.2]pentacenophane $\mathbf{6}$, a blue solid that is moderately soluble in organic solvents. The bathochromic shift $(\sim 20 \mathrm{~nm})$ of $\mathbf{6}$, compared to pentacene monomer $\mathbf{7}$, is attributed to coupling between the pentacene subunits. It would be interesting to build off of this result by comparing the device performance of $\mathbf{6}$ and related pentacenophanes to their respective pentacene monomers. 